\section{Viure menys anys i en pitjor salut: el peatge de la població amb menor nivell educatiu a Espanya}

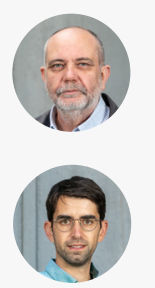

\author{
Amand Blanes \\ Investigador (CED) \\ Sergi Trias-Llimós \\ Investigador Juan de la Cierva (CED)
}

Més de tres anys separen l'esperança de vida als 30 anys dels grups més intruïts en relació als que tenen uns nivells educatius més baixos. A les darreres dècades s'ha produït una substancial millora en la longevitat de la població espanyola, però aquestes millores emmascaren la persistència de significatives desigualtats en salut i mortalitat. El nivell socioeconòmic discrimina l'estat de salut de les persones al llarg de la seva vida, essent l'educació un dels indicadors més emprats en els estudis sobre desigualtats socials en mortalitat i salut. El nivell educatiu, a més de ser una variable indirecta de la situació socioeconòmica, condiciona en gran mesura els estils de vida i les preferències cap a la salut de les persones, així com l'ús que fan dels recursos del sistema sociosanitari. En aquest número de Perspectives Demogràfiques abordem les diferències actuals de mortalitat i salut a Espanya segons el nivell educatiu. Aquestes desigualtats poden resumir-se com una triple penalització de les persones amb menys educació en relació amb les més instruïdes: a) una menor esperança de vida; b) una major desigualtat en l'edat a la mort; i c) una menor proporció de la seva vida amb qualitat de vida.

\section{Duracions i equitat de vida segons nivell educatiu}

La influència de l'educació en la mortalitat i la salut presenta un clar gradient on els grups amb nivells educatius baixos gaudeixen de menys esperança de vida i pitjors condicions de salut en relació amb els grups més formats (Permanyer et al. 2018; Solé-Auró, 2020). La primera penalització s'observa en termes d'esperança de vida. A Espanya, el 2017-19, els homes amb estudis superiors podien esperar viure a partir dels 30 anys uns 5 anys més que els que tenien estudis primaris o inferiors $(53,5 \mathrm{vs}$ 48,4 anys), mentre que aquesta diferència era menor en les dones, d'una mica més de 3 anys (58,0 vs 54,9 anys). El paper de l'educació és més discriminatori en la població masculina, ja que les diferències entre els que tenen estudis secundaris i els superiors són rellevants en els homes i menys significatius en les dones. Les desigualtats en esperança de vida entre homes i dones tendeixen a disminuir a mesura que augmenta el nivell educatiu, reflectint que els comportaments i els factors de risc són més homogenis entre la població més educada.

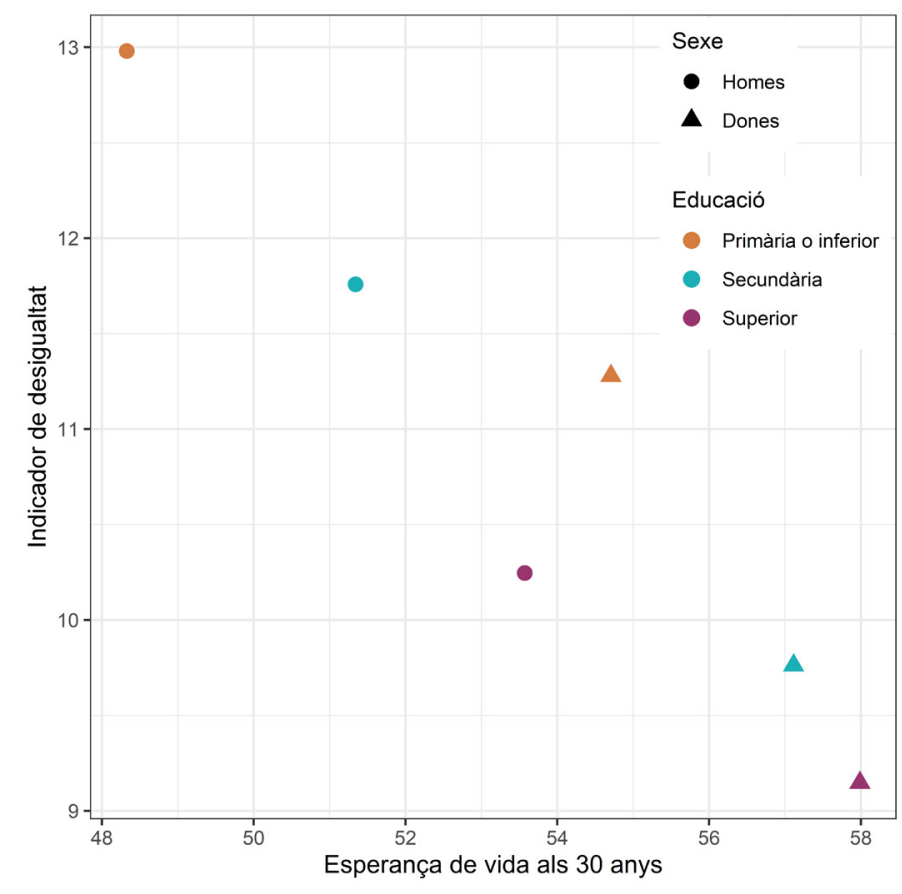

Figura 1. Esperança de vida i desigualtat en l'edat a la mort (lifespan inequality) a l'edat 30 segons sexe i nivells educatiu. Espanya 20172019. Nota: l'indicador desigualtat en l'edat a la mort s'ha calculat entre l'edat 30 i la 94.. Font: elaboració a partir de les microdades de defuncions i de les Cifras de población segons nivell educatiu de l'INE. 
L'esperança de vida permet comparar les desigualtats de supervivència entre els nivells educatius, però no proporciona informació sobre la menor o major equitat davant la mort dins de cadascun d'ells ${ }^{1}$. Als darrers anys s'han desenvolupat una sèrie d'indicadors que, englobats sota el concepte de Lifespan inequality, mesuren la desigualtat a l'edat a la mort (Aburto et al. 2020). Els resultats per a Espanya són il-lustratius de la segona penalització que pateix la població amb nivells educatius baixos, especialment la masculina, ja que a la seva menor esperança de vida s'afegeix una major dispersió de l'edat a la defunció o, en altres paraules, a una major desigualtat de supervivència entre els seus membres (figura 1). Entre la població amb estudis superiors, i entre les dones també amb educació secundària, les duracions de la vida no sols són de mitjana més llargues sinó que també són més homogènies, reflectint una major equitat en la supervivència. A Espanya, la desigualtat a l'edat a la mort de la població amb estudis primaris o inferiors supera a l'observada en el col-lectiu amb estudis superior en un $27 \%$ en els homes i en un $23 \%$ en les dones.

L'explicació de les desigualtats de vida entre i dintre dels nivells educatius requereix abordar els patrons de mortalitat per causa, ja que permeten esbossar una pri- mera aproximació als seus factors subjacents. Aquesta anàlisi és especialment rellevant per a la població adulta i madura per dues raons: d'una banda, són les edats on els diferencials relatius en els riscos de morir entre grups educatius són més acusats; d'altra, una part de les morts que es produeixen en aquestes edats es consideren evitables per polítiques preventives intersectorials de salut pública i/o per tractaments i assistència mèdica . A Espanya, al 2017-2019, la mortalitat per causes evitables va representar al voltant del 60-70\% de les morts d'entre 30 i 74 anys tant en els homes com en les dones. En la població de 30 a 49 anys, la taxa de mortalitat per causes evitables de la població menys instruïda multiplica per 3,4 en els homes i per 2,4 en les dones a la de la població amb estudis superiors, i en el grup de 50-74 anys aquestes ràtios se situen en 2,1 i 1,5 respectivament (figura 2). En general, les causes relacionades amb comportaments i estils de vida (per exemple, el consum de tabac i/o alcohol) tenen un major pes relatiu en els homes que en les dones. Des dels 30 als 49 anys, entre les principals causes evitables amb diferències significatives de mortalitat entre els nivells educatius baixos i els alts es troben el càncer de pulmó, les malalties isquèmiques i els accidents de trànsit en ambdós sexes, així com els suïcidis, els altres accidents i
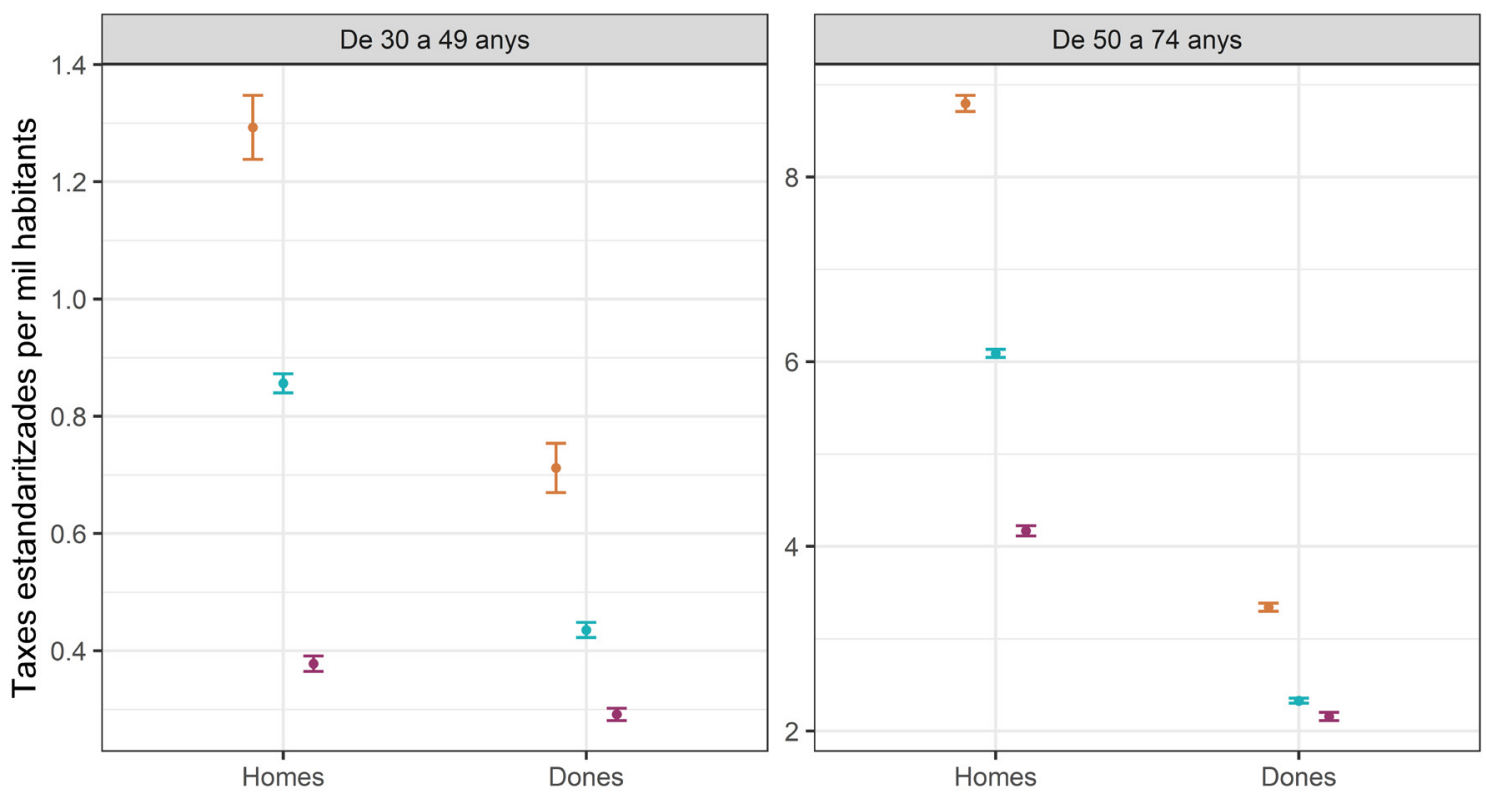

$\rightarrow$ Primària $\circ$ inferior $\rightarrow$ Secundària $\rightarrow$ Superior

Figura 2. Taxes estandarditzades de mortalitat per causes evitables per grup d'edat, sexe i nivell educatiu. Espanya 2017-19. Nota: taxes estandarditzades amb l'European Standard Population 2013. Font: elaboració a partir de les microdades de defuncions i de les Cifras de población segons nivell educatiu de l’INE.

${ }^{1}$ Dues poblacions poden gaudir d'una esperança de vida relativament similar, per exemple 75 anys, però en una les defuncions de la taula de mortalitat es concentren al voltant d'aquesta edat mentre que en l'altra es troben més disperses, i per tant és més equitativa la distribució de les durades de la vida en la primera població que en la segona.

${ }^{2}$ S'ha emprat la llista Avoidable mortality: OECD/Eurostat lists of preventable and treatable causes of death (November 2019 version) 
les morts per consum d'alcohol o drogues en els homes, i les morts cerebrovasculars en les dones. En la població de 50 a 74 anys, les diferències significatives de mortalitat entre els nivells educatius es donen, entre d'altres causes, en les malalties isquèmiques, les cerebrovasculars i el càncer colorectal en ambdós sexes, a més del càncer de pulmó i fetge en els homes, i el d'úter en les dones. La relació a major educació menor mortalitat evitable presenta una significativa excepció en el càncer de pulmó en les dones de 50 a 74 anys, ja que va ser la població amb major nivell educatiu la primera en adoptar de forma important l'hàbit de fumar, mentre que en les cohorts més recents les taxes de mortalitat per aquesta causa de mort són ja més altes en les dones amb un nivell educatiu baix.

\section{La desigualtat en salut}

Les desigualtats en mortalitat, presentades com a primera i segona penalització, són la punta de l'iceberg d'un conjunt més ampli de desigualtats socioeconòmiques en salut. La percepció dels individus sobre la seva pròpia salut també presenta un clar gradient segons el nivell educatiu, ja que els grups amb nivells educatius baixos pateixen una tercera penalització degut a una major prevalença de males condicions de salut autopercebuda i de limitacions pel desenvolupament d'activi- tats (figura 3). A diferència de la mortalitat, el paper que exerceix el nivell educatiu és més discriminatori en les dones, ja que la mitjana d'anys que poden esperar viure en bona o molt bona salut a partir dels 30 anys és de 29,5 anys entre les menys formades i de 44,2 anys entre les que tenen estudis superiors (més de 14 anys de diferència, un 50\% més), mentre que aquests valors són de 30,9 i 41,0 anys en els homes (10 anys de diferència, un 33\% més els d'educació superior). Altres indicadors de salut, com l'esperança de vida sense limitacions moderades o severes per al desenvolupament d'activitats quotidianes de la vida, tenen un gradient per nivell educatiu similar al de l'estat de salut autopercebuda.

A partir dels 30 anys, els homes amb nivells educatius més baixos tenen una esperança de vida sense limitacions 8 anys inferior a la dels més educats, mentre que en les dones aquesta diferència s'apropa als 11 anys. Si es mantinguessin les actuals condicions de salut i mortalitat de la població espanyola, les desigualtats entre grups educatius en relació amb la qualitat dels anys de vida, l'autonomia personal i la dependència serien molt significatives. Així, les dones amb nivells educatius baixos només gaudirien de bona o molt bona salut durant poc més de la meitat dels anys restants de la seva vida a partir del seu trentè aniversari, mentre que les que tenen estudis superiors percebrien la seva salut com a

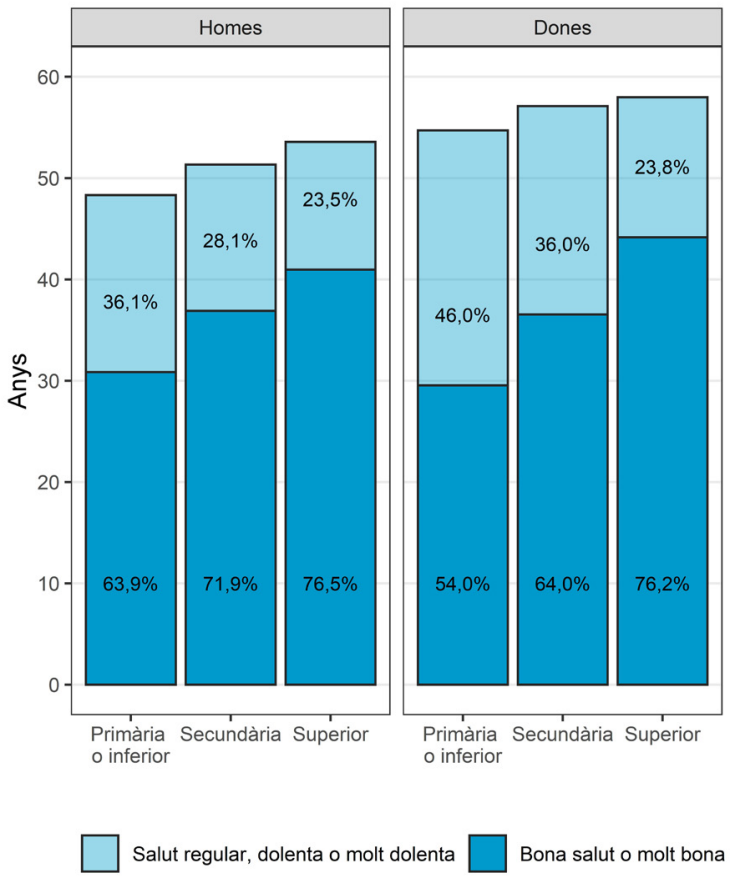

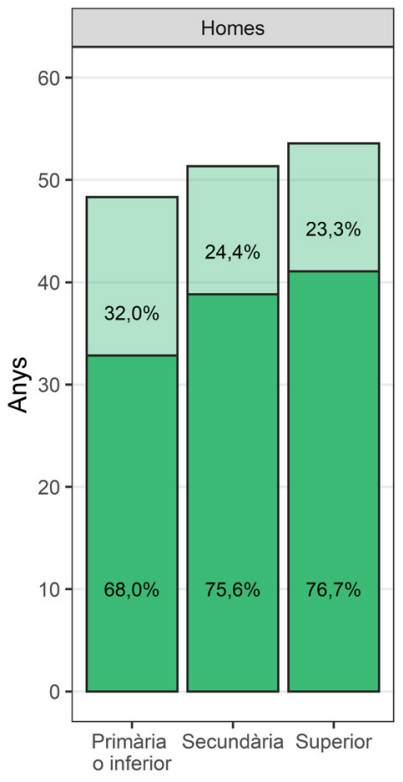

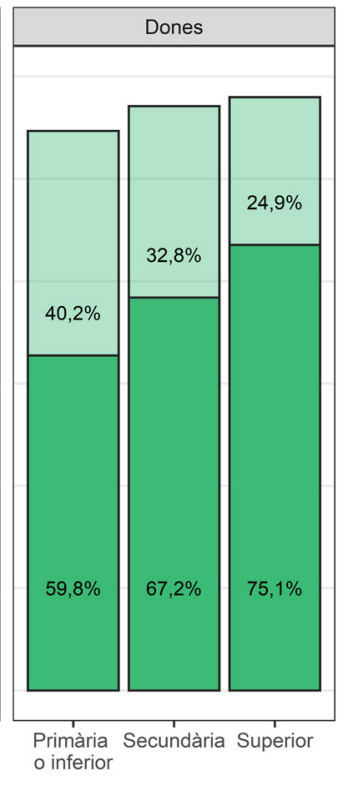

Amb limitació moderada o severa 
bona durant tres quartes parts de la seva vida.

La paradoxa del gènere en la salut s'observa quan analitzem el conjunt de la població, ja que les dones viuen més temps, però ho fan amb pitjors condicions de salut. No obstant, aquesta dicotomia entre mortalitat i morbiditat es matisa quan es considera el nivell educatiu, ja que entre la població amb estudis superiors el percentatge d'anys de vida en bona salut o sense limitacions és similar entre homes i dones, tot i que aquestes hi viuen més temps. Per contra, per a la població amb un nivell educatiu més baix, i en menor mesura per a la població amb educació secundària, els anys de vida de més que viuen les dones en relació als homes són anys de salut autopercebuda regular o dolenta. En aquest sentit, el canvi generacional, associat a la progressiva arribada a edats avançades de generacions de dones cada vegada més educades, pot contribuir en les pròximes dècades a una millora de les condicions de salut del conjunt de la població femenina i a una reducció de les bretxes de salut entre homes i dones.

\section{Conclusions i perspectives}

En aquest Perspectives Demogràfiques hem analitzat les desigualtats socioeconòmiques en salut $\mathrm{i}$ mortalitat a Espanya, a partir de la triple penalització que pateix la població amb un nivell educatiu baix en relació amb les persones amb estudis superiors. No obstant, en la interpretació dels resultats cal considerar que s'han calculat amb dades d'un període concret $\mathrm{i}$, per tant, mesuren quines serien les desigualtats si es mantinguessin en el futur els actuals patrons de salut i mortalitat de la població espanyola. A més, cal tenir en compte que també hi ha un efecte de la salut sobre l'educació, ja que en alguns individus són les seves condicions de salut les que determinen els seus nivells educatius.

Durant els propers anys, l'augment dels nivells educatius de la població gran degut al canvi generacional, especialment entre les dones, jugarà un paper positiu sobre els nivells agregats de salut $\mathrm{i}$ mortalitat de la població. No obstant, aquest canvi ha d'anar acompanyat del disseny de polítiques que mitiguen les desigualtats entre i dins dels diferents grups socioeconòmics, especialment si considerem el marge de millora que encara existeix, controlant, per exemple, els factors subjacents a la mortalitat evitable. Aquests factors estan relacionats amb els hàbits i estils de vida, amb les condicions de treball i l'estatus, amb el que es coneix com a "alfabetització en salut”, o amb l'ús del sistema sociosanitari, entre d'altres. Els factors anteriors remeten en darrera instància a les desigualtats socials i econòmiques que encara persisteixen en la nostra societat. La necessitat d'articular polítiques que abordin l'arrel d'aquestes desigualtats serà encara més urgent a causa dels efectes socials i econòmics derivats de la COVID-19.
Referències bibliogràfiques Aburto, J. M.; Villavicencio, F.; Basellini, U.; Kjærgaard, S.; Vaupel, J. W. (2020) "Dynamics of life expectancy and life span equality". Proceedings of the National Academy of Sciences, 117 (10): 5250-5259 (DOI: 10.1073/pnas.1915884117)

Permanyer, I.; Spijker, J.; Blanes, A.; Renteria, E. (2018) "Longevity and lifespan variation by educational attainment in Spain: 1960-2015”. Demography, 55 (6): 2045-2070 (DOI: 10.1007/s13524-018-0718-z).

Solé-Auró, A.; Martín, U.; Domínguez Rodríguez, A. (2020) "Educational inequal-ities in life and healthy life expectancies among the 50-plus in Spain". International journal of environmental research and public health, 17 (10), 3558: 1-10 (DOI: 10.3390/ijerph17103558).

\section{Citc}

Blanes, A.; Trias-Llimós, S. (2021) “Vivir menos y con peor salud: el peaje de la población menos instruida en España”. Perspectives Demogràfiques, 24: 1-4 (ISSN: 2696-4228). DOI: 10.46710/ced.pd.esp.24

ISSN

ISSN 2696-4228

DOI

https://doi.org/10.46710/ced.pd.cat.24

Editors

Andreu Domingo y Albert Esteve (CED)

Correspondència dirigida a

Sergi Trias Llimós (strias@ced.uab.es)
Crédits

Gràfios: Anna Turu

Maquetació: Eva Albors i Xavier Ruiz

Agraïments

Volem agrair a l'Instituto Nacional de Estadística haver-nos facilitat les dades de les Cifras de Población desagregades segons nivell educatiu dels anys 2018 i 2019.

\section{Finançament}

Sergi Trias-Llimós gaudeix d'una beca del programa Juan de la Cierva del Ministerio de Ciencia e Innovación (FJC2019039314-I) i participa en el projecte HEALIN (ERC-2019-COG, No 864616).
Direcció Twitter @CEDemografia

Contacte

Centre d'Estudis Demogràfics.

Carrer de Ca n’Altayó, Edifici E2

Universitat Autònoma de Barcelona

08193 Bellaterra / Barcelona

Espanya

+34935813060

demog@ced.uab.es

ced.uab.cat

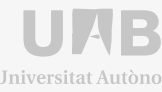

